\title{
STANDARDIZATION OF MODEL OF INDUCTION OF HEPATOTOXICITY WITH ANTITUBERCULOSIS DRUGS IN WISTAR ALBINO RATS
}

\author{
SARITA M KAPGATE*, ABHIJIT B PATIL \\ Department of Agada Tantra, Bharati Vidyapeeth Deemed University College of Ayurved, Pune - 411 043, Maharashtra, India. \\ Email: drsaritakapgate@gmail.com
}

Received: 01 April 2016, Revised and Accepted: 11 March 2017

\section{ABSTRACT}

Objective: The objective of the study to standardize the model of hepatotoxicity induced by ATT drugs in Wistar Albino rats. Isoniazid (INH), rifampicin (RMP), pyrazinamide (PZA), the first line drugs used in the treatment of tuberculosis (TB) associated with the potential adverse effect. Numerous animal studies were reported endeavoring induction and cure of anti-TB (ATT) drug-induced hepatotoxicity using herbal and chemical drugs. However, the previous reported study failed to replicate where Wistar albino rats were treated with INH, RMP, and PZA and had shown the significant development of liver injury. Hence in present paper, aimed to develop a standardize model of induction of hepatotoxicity with ATT drugs.

Methods: Wistar rats were treated with ATT drugs in combination in various doses up to 4-8 weeks. Total nine experiments were conducted to achieve successful hepatotoxicity. The aspartate aminotransferase (AST), alanine aminotransferase (ALT), and alkaline phosphatase (ALP) were the biochemical parameters of assessment. Histopathological changes in the liver were also examined.

Results: No evidence of any liver injury or an inflammatory infiltrate has been observed as had been reported in the previous studies. Rather decrease in serum ALT levels has been observed by researcher. In short, hepatic injury cannot be developed with the doses used in previous reported papers. The successful attempt to induce hepatotoxicity can be achieved with the doses of INH - 100, RMP - 300, PZA - 700 mg/kg. The findings were confirmed by the raised ALT, AST, and ALP levels compared with baseline. The histopathological changes also support the findings.

Conclusion: The dose of INH - 100, RMP - 300 and PZM - $700 \mathrm{mg} / \mathrm{kg}$. Succeeds to induce hepatotoxicity in Wistar albino rats and Swiss albino mice as well.

Keywords: Hepatotoxicity, Wistar albino rats, Antituberculosis drugs.

(C) 2017 The Authors. Published by Innovare Academic Sciences Pvt Ltd. This is an open access article under the CC BY license (http://creativecommons. org/licenses/by/4. 0/) DOI: http://dx.doi.org/10.22159/ajpcr.2017.v10i6.11971

\section{INTRODUCTION}

Tuberculosis (TB) caused due to tubercle bacillus has been recognized as a clinical entity since the ages of Hippocrates (460-370 BC). About onethird of the world's population has latent TB and roughly 9 million cases of active TB emerge annually resulting in about 2-3 million deaths [1] exhibits the magnitude and importance of the problem. Moreover, the most populated nations like India and China [2] are on alarming bomb. WHO report 2013 stated that India had largest number of cases $26 \%$ of whole globe [3]. Furthermore, higher risk of hepatotoxicity due to ATT has been reported in Indians (up to $11.5 \%$ ) than Western population (up to $4.3 \%$ ) [3]. In current scenario, the world's TB problem is bigger than before because of HIV infection as well as multiple drug resistant $\mathrm{TB}$ due to inefficient management of TB.

The recommended treatment regimen for $\mathrm{TB}$ is the combination chemotherapy containing isoniazid (INH), rifampicin (RMP) and pyrazinamide (PZA) with or without ethambutol [4]. However, potential hepatotoxicity of the first-line antitubercular agents is an associated problem, especially during the initial period of treatment [5]. The malnutrition and alcohol consumption reported to enhance the incidence of hepatotoxicity [6]. It has been reported the prevalence of adverse drug reaction of anti-TB (ATT) drugs are more in females $(55 \%)$ than in males (45\%). The adverse drug reactions reported other than hepatotoxicity are symptoms affecting to skin and appendages $(23.56 \%)$ gastrointestinal system $(19.28 \%)$ and the musculoskeletal system (15.7\%) [7].
Animal models mimicking liver disease and related toxicity are being used for several decades to study the hepatotoxicity induced by ATT drugs. In addition, many attempts were reported to find hepatoprotective drug against the ATT induced hepatotoxicity. It has been reported that INH, RMP, PZA in combination in the doses of 7.5, 10 and $35 \mathrm{mg} / \mathrm{kg} /$ day, respectively, induced hepatotoxicity [8-10]. In another study, antitubercular drugs were used in dose of INH - 27, RMP - 54, PZA - $135 \mathrm{mg} / \mathrm{kg} /$ day claimed the induction of hepatotoxicity [11]. Researcher endeavored to replicate the studies to induce hepatotoxicity using the same dose in same species but failed to develop hepatotoxicity.

Hence, further attempts have been taken to achieve successful induction of hepatotoxicity with higher doses using animal model.

\section{Aim}

The aim of the study is to develop an animal model of antitubercular drug-induced hepatotoxicity in Wistar rats.

\section{METHODS}

- Animals: Wistar albino rats and Swiss albino mice

- Chemical agents: INH, RMP, PZA in combination was used to induce hepatotoxicity, supplied in pure powder form by Macleodos Pharmaceuticals, Mumbai, India as a gift sample

- Bioassay kits: Liver enzyme activities were measured using the Bioassay kits, procured by Coral Clinical System of Tulip group. 


\section{Study protocol}

The study protocol was duly approved by the Institutional Animal Ethics Committee. Studies were performed in accordance with the CPCSEA guidelines. Healthy adult albino Wistar rats of either sex weighing between 150 and $200 \mathrm{~g}$ were used in experiment. For one experiment, Swiss Albino mice of 6-8 weeks were also used. Animals were fed with standard diet and water under strict hygienic conditions. After acclimatized for 7 days, under laboratory conditions animals were randomized into groups $(n=4)$ and administered with ATT drug in combination to induce hepatotoxicity. Sterile water was given to control group. INH was dissolved in distilled water whereas RMP was first dissolved in $0.5 \mathrm{ml}$ of $0.1 \mathrm{~N} \mathrm{HC} 1$ and then made up to the required volume by adding sterile distilled water. The $\mathrm{pH}$ of the solution was tried to maintain approximately 6.5 and PZA was suspended in distilled water. Total nine attempts have been conducted in accordance of different reported papers to induce hepatotoxicity wherein different dose level, route of administration, types of rodents has been tested for toxicity. The details of conducted nine experiments to establish a model of hepatotoxicity induced by ATT drugs have been showed in Table 1.

At endpoint, animals were sacrificed and blood was collected by cardiac puncture under light ether anesthesia. The first abdomen was opened by taking a midline incision. Then, diaphragm was cut with precaution to expose beating heart. By using 24 gauge needles, blood was collected slowly from the left ventricle in plain bulb for biochemical analysis. The liver was dissected by cutting surrounding attachments preserved in $10 \%$ formalin in plastic jars and was sent for histopathological investigation.

Parameters of evaluation to confirm the evidence of hepatotoxicity:

A. Biochemical parameters:

- Serum alanine aminotransferase (ALT) (Reitman \& Frankels method)

- Serum aspartate aminotransferase (AST) (Reitman \& Frankels method)

- Alkaline phosphatase (ALP) (Mod. Kind \& King's method).

B. Histopathological parameters - Histopathological assessment of liver damage was done by using hematoxylin and eosin staining, paraffin block method [12].

\section{Statistical analysis}

As the number of animals in each group was few $(n=4)$ and the data does not follow normal distribution non-parametric tests the MannWhitney (for two groups comparison) was applied.

\section{RESULTS}

In first experiment where the albino Wistar rats were treated with the dose of $7.5 \mathrm{mg} / \mathrm{kg} /$ day of isoniazid, $10 \mathrm{mg} / \mathrm{kg} /$ day of RMP, and $35 \mathrm{mg} / \mathrm{kg} /$ day of PZA for 21 days as per the reported study [8-10] showed no evidence of induction of hepatotoxicity on the biochemical parameters. Furthermore, no histological changes have been observed as well. In the second experiment in which the same dose was used for 30 days no raise in liver enzymes have been observed. Then, in the third experiment, no signs of induction of hepatotoxicity on biochemical and histological have been recorded. In this experiment, higher dose was selected for hepatotoxicity induction which was INH $27 \mathrm{mg} / \mathrm{kg} /$ day, RMP $54 \mathrm{mg} / \mathrm{kg} /$ day, and PZA $135 \mathrm{mg} / \mathrm{kg} /$ day for 35 days by oral route as a reported study [11]. Thus, no significant elevation of liver enzyme has been observed. The effect of ATT drugs on serum AST, ALT and ALP has been tabulated in Table 2 .

The fourth experiment wherein double dose of the previous study, i.e., 54, 108, and $270 \mathrm{mg} / \mathrm{kg} /$ day INH, RMP and PZA, respectively, was used by oral route but still no elevation of AST, ALT and ALP was observed. The AST was $258 \pm 103.33$ at baseline versus $192.66 \pm 16.16$, ALT was $78.66 \pm 22.89$ at baseline versus $41 \pm 17.43$ and ALP was $481 \pm 9.53$ at baseline versus $184 \pm 29.59$ at day 60 . To rule out the sensitivity of the animals of the source in fifth experiment animals of another authorized animal house was obtained. For this experiment, the animals were treated with the previous reported study as INH - 27, RMP - 54 and PZA - $135 \mathrm{mg} / \mathrm{kg} /$ day for 35 days by oral route [11]. However, the animals did not show evidence of hepatotoxicity (data not shown). To understand failure of induction of hepatotoxicity a critical review of available literature was done again. Some studies revealed intra peritoneal administration of INH and RMP to induce hepatotoxicity. Hence, next sixth experiment was carried out with the doses of 50 and $100 \mathrm{mg} / \mathrm{kg} /$ day of INH and RMP, respectively, by IP route and PZA by oral route in the doses of $350 \mathrm{mg} / \mathrm{kg} /$ day for 60 days. In this experiment, also no evidence of toxicity was observed. The assay was repeated on day 21, 30, 45 and 60 The AST was 312.5 \pm 159.28 , ALT was $100.25 \pm 22.23$ and ALP was $367.75 \pm 117.64$ as a baseline values whereas AST was $193.75 \pm 34.64$, ALT was $49.25 \pm 15.06$ and ALP was $156.75 \pm 40.45$ as a day 60 values. Thus, no induction of hepatotoxicity can be recorded rather significant reduction in the liver enzyme activity was observed at endpoint when compared with baseline levels.

In the seventh experiment where double dose of the previously used doses in Wistar rats, i.e., $100 \mathrm{mg} / \mathrm{kg} /$ day of INH, $300 \mathrm{mg} / \mathrm{kg} /$ day of RMP and $700 \mathrm{mg} / \mathrm{kg} /$ day of PZA was used, the liver enzymes showed approximately three-fold elevation when compared with base line enzymes (Fig. 1). In eighth experiment similar doses used in Swiss albino mice by intra gastric route for 21 days also showed raised AST, ALT and ALP. The bioassays ALT and AST were done at baseline, day 15 and 21 whereas ALP was done on baseline and day 21 (Fig. 2). But when the same dose was tried to administer by intra peritoneal route in albino mice, the animals showed mortality on day 2,3,4 one animal each and could not be completed. Thus, successful hepatotoxicity can be induced by the ATT drugs in the doses of $100 \mathrm{mg} / \mathrm{kg} /$ day of INH, $300 \mathrm{mg} / \mathrm{kg} /$ day of RMP and $700 \mathrm{mg} / \mathrm{kg} /$ day of PZA for 21 days in Wistar rats as well as Swiss mice.

The body weight of the animals in control and treated animals has no difference in the previous experiments, but in past two successful experiments, the treated animals showed marked loss in body weight in first 15 days but in next 7 days they continued to gain body weight throughout the treatment. The average increase in the weight of animals in the groups where no induction is seen was $80.11 \mathrm{~g}$, whereas average increase in weight in successful hepatotoxicity induction experiment

Table 1: List of experiments executed to standardize the model of ATT induced hepatotoxicity

\begin{tabular}{|c|c|c|c|c|c|c|}
\hline Experimental No. & INH (mg/kg/day) & RMP (mg/kg/day) & PZA (mg/kg/day) & $\begin{array}{l}\text { Route of } \\
\text { administration }\end{array}$ & Strain of animals & $\begin{array}{l}\text { Duration of } \\
\text { administration }\end{array}$ \\
\hline 1 & 7.5 & 10 & 35 & Oral & Wistar Albino rats & 21 days \\
\hline 2 & 7.5 & 10 & 35 & Oral & Wistar Albino rats & 30 days \\
\hline 3 & 27 & 54 & 135 & Oral & Wistar Albino rats & 35 days \\
\hline 4 & 54 & 108 & 270 & Oral & Wistar Albino rats & 60 days \\
\hline 5 & 27 & 54 & 135 & Oral & Wistar Albino rats & 35 days \\
\hline 6 & 50 (IP) & 100 (IP) & 350 (Oral) & IP and OP & Wistar Albino rats & 60 days \\
\hline 8 & 100 & 300 & 700 & Oral & Swiss Albino mice & 21 days \\
\hline 9 & 100 & 300 & 700 & IP and OP & Swiss Albino mice & 21 days \\
\hline
\end{tabular}

ATT: Antituberculosis, INH: Isoniazid, RMP: Rifampicin, PZA: Pyrazinamide 
Table 2: Effect of ATT drugs on liver markers serum AST, ALT and ALP

\begin{tabular}{llll}
\hline Experimental No. & Bioassay & $\begin{array}{l}\text { Control } \\
\text { group }\end{array}$ & $\begin{array}{l}\text { Treatment } \\
\text { group }\end{array}$ \\
\hline 1 & AST IU/L & $119 \pm 23.9$ & $97 \pm 12.98$ \\
& ALT IU/L & $183.5 \pm 15.45$ & $175.75 \pm 28.61$ \\
& ALP U/L & $287.75 \pm 55.56$ & $261.25 \pm 33.62$ \\
& AST IU/L & $166.66 \pm 11.54$ & $133.5 \pm 19.43$ \\
& ALT IU/L & $58 \pm 27.05$ & $52.75 \pm 11.87$ \\
3 & ALP U/L & $171.25 \pm 26.53$ & $154.66 \pm 22.23$ \\
& AST IU/L & $268.25 \pm 62.66$ & $200 \pm 60.94$ \\
& ALT IU/L & $100.55 \pm 44.77$ & $65 \pm 10.73$ \\
& ALP U/L & $287.75 \pm 92.43$ & $210.25 \pm 92.4$ \\
\hline
\end{tabular}

The number of animals used in each experiment was n=04. AST: Aspartate aminotransferase, ALT: Alanine aminotransferase, ALP: Alkaline phosphatase

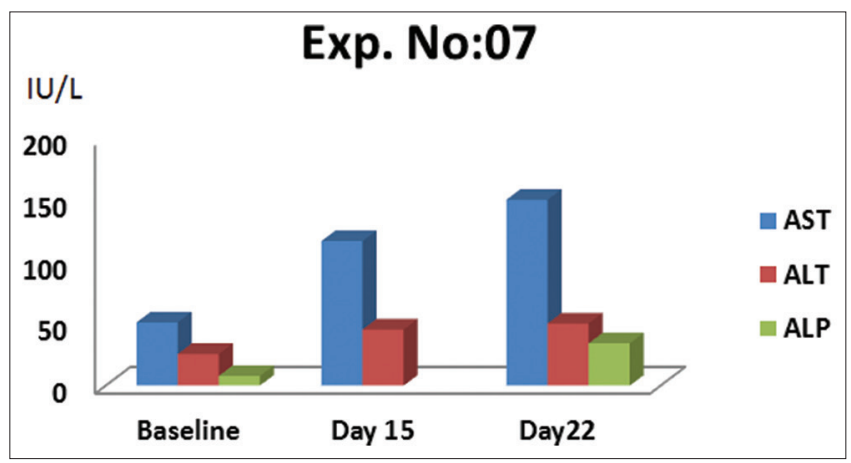

Fig. 1: Results of liver enzyme activity in Wistar rats $(n=04)$

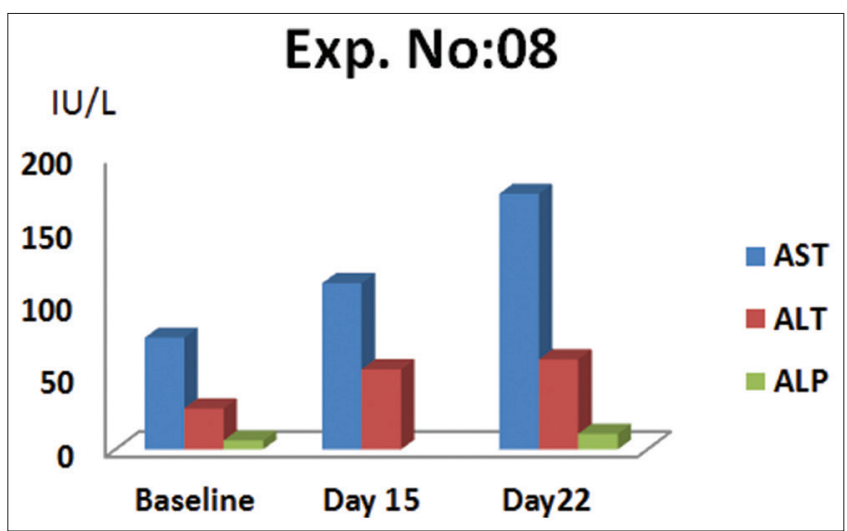

Fig. 2: Results of liver enzyme activity in Swiss mice (n=04)

was seen $7 \mathrm{~g}$ in Wistar rats and loss of $0.2 \mathrm{~g}$ was seen in mice. In the liver cell of animals where successful hepatotoxicity induction was noted, it was observed that hepatocytes are swollen. Some of them are necrotic without nuclei, prominent Kupffer cells, intracellular bile pigment is seen focally, sinusoids appear congested and compressed. Some slides showed focal collection of lymphocytes and microphages near the central veins.

\section{DISCUSSION}

Therapeutic drug-induced toxicity is a major concern in treatment of many diseases. As liver plays a major role in drug metabolism is usually exposed to drug induced hepatoxicity. Numerous therapeutic chemical drugs are associated with hepatotoxicity as a potential adverse effect and main hinder in the treatment. Several mechanisms initiate liver cell damage and aggravate ongoing injury processes. Mitochondria are prominent targets for the hepatotoxicity of many drugs. Dysfunction of these vital cell organelles results in impairment of energy metabolism and oxidative stress with excessive formation of reactive oxygen species and peroxynitrite. In addition to mitochondria, induction of cytochrome P450 isoenzymes such as CYP2E1 also promotes oxidative stress and cell injury. Once hepatocellular function is impaired, accumulation of bile acids causes additional stress and cytotoxicity. Cell injury, gutderived endotoxin or a combination of both activate Kupffer cells too and recruit neutrophils into the liver. Although responsible for removal of cell debris and part of the host-defense system, under certain circumstances these inflammatory cells initiate additional liver injury. Thus because of the many direct and indirect mechanisms of druginduced cell injury in the liver, hepatotoxicity is a major reason for drug withdrawal from pharmaceutical development and clinical use [13].

INH, RMP, and PZA remain a mainstay in the treatment of TB; however, associated hepatotoxicity is serious concern and needs evaluation of some adjuvant hepatoprotective agent. Because of the ethical concern and experimental difficulties in studying drug induced toxicity in human, a substantial portion of research related to drug induced hepatotoxicity has used animals as experimental model. A robust and valid experimental model is essential to derive a conclusive and reliable solution. To establish such model attempts have been taken using different doses, route of administration, duration and rodents.

The incidence of ATT drug induced hepatotoxicity varies worldwide and reported to be higher in developing countries. Factors such as malnutrition, acute or chronic liver disease, dominance of diseases such as HIV and diabetes, alcoholic liver disease, indiscriminate use of drugs, and more advanced TB may be the contributed to higher incidence in developing nations $[14,15]$. Overall, hepatotoxicity attributed to anti-TB drugs has been reported in $5 \%-28 \%$ of patients treated with anti-TB drugs [16]. Considering the high incidence of anti-TB drugs-induced hepatotoxicity in humans, the development of hepatic injury with combination of anti-TB drugs is a challenging task. This may be due to the absence of diseased condition, TB in the animals.

The exact mechanism of ATT drugs is not explored clearly but metabolic idiosyncratic reactions [17] and oxidative stress [18] appear to be responsible for hepatic injury in humans. However, recently immune mediated mechanism is claimed as a cause of isoniazid induced hepatotoxicity [19]. Studies have reported high hepatotoxic levels of the INH metabolites reach much earlier when INH plus RMP is administered together than INH alone for treatment and has been shown to be synergistic rather than additive [20]. RMP increases the metabolism of INH to isonicotinic acid, which is a hepatotoxic product. Furthermore, RMP shortened the plasma half-life of acetyl hydrazine, an INH metabolite and acetyl hydrazine is quickly converted to its active metabolites by increasing the oxidative elimination rate of acetyl hydrazine, which leads to occurrence of liver necrosis [21]. Besides RMP is a potent inducer of CYP2E1 isoenzymes and plays a key role to increase formation of its toxic metabolite hydrazine and thereby enhance INH induced toxicity [22]. Thus RMP contributes to increase toxicity of INH. Addition of PZA to INH and RMP further enhances the hepatotoxicity. PZA first metabolized to pyrazinoic acid (PA) by the enzyme liver microsomal amidase and further oxidized by enzyme xanthine oxidase to 5-hydroxy PA $[23,24]$. These two reactive metabolites of PZA are considered to have hepatotoxic potential.

The previous reported studies [8-11] wherein a successful induction of hepatotoxicity was claimed were tried to replicate in six experiments but no evidence of toxicity was seen. Instead of raise in ALT level decrease of ALT has been observed in these experiments. This may be contributed to the INH. It is now accepted that ALT is inhibited by INH, mainly because INH forms a Schiff base with pyridoxal 5 -phosphate, which is required co-factor in the ALT assay [25-27].

ALT, AST and ALP level showed noteworthy raise when the dose of ATT drug has been increased to higher levels of PZA. Studies have shown that TB patients treated with PZA, $16 \%$ had increased liver enzymes, $7.9 \%$ had 5 times more liver enzymes than normal, and $5.3 \%$ had 
hepatitis symptoms [28,29]. Furthermore, Yee et al. also concluded on the basis of survey findings conducted on 430 patients of TB, the drug most likely responsible for the occurrence of hepatitis is PZA [30].

These data support the claim that role of PZA is likely more to raise levels of liver enzymes.

It has been also noted that animals of the control and treated group gained comparable body weight in the experiments where the previous reported dose were tried to reproduce. However in the past two successful experiments, the treated animals showed marked loss in body weight in first 15 days but in next 7 days they continued to gain body weight throughout the treatment. This pattern may be due to the tendency of the animals to adapt the drug toxicity. During the experiment, it was also noted that the animals of the same group may show different response with respect to changes in biochemical assay or body weight contributed to the idiosyncratic reaction of the drug.

\section{CONCLUSION}

Although we fail to replicate the previous studies, the successful hepatotoxicity has been induced with the dose INH - 100, RMP - 300, and PZA $700 \mathrm{mg} / \mathrm{kg}$ at day 21.

\section{ACKNOWLEGMENT}

Dr. Vijaya Pandit, Dr. Karandikar, Dr. Supriya Bhalerao, Sheetal Giramkar for execution of experiment.

\section{REFERENCES}

1. Raviglione MC, Snider DE Jr, Kochi A. Global epidemiology of tuberculosis. Morbidity and mortality of a worldwide epidemic. JAMA 1995;273(3):220-6.

2. World Health Organization. Global Tuberculosis Control: Surveillance, Planning, Financing. WHO Report; 2002. p. 237. Available from: http:// www.popline.org/node/237595.

3. Steele MA, Burk RF, DesPrez RM. Toxic hepatitis with isoniazid and rifampin. A meta-analysis. Chest 1991;99(2):465-71.

4. Chan ED, Iseman MD. Current medical treatment for tuberculosis. BMJ 2002;325(7375):1282-6.

5. Mahashur AA, Prabhudesai PP. Hepatitis and antitubercular therapy. J Assoc Physicians India 1991;39(8):595-6.

6. Ika FB, Erna KS. Decrease of liver function after treatment of antituberculosis drugs in tuberculosis patients with malnutrition and alcohol consumption Int J Pharm Pharm Sci 2016;8(7):269-73.

7. Siddiqui S, Mirza MA, Jaffer S, Ansari SF. Study on prevalence of adverse drug reactions in patients suffering from tuberculosis in a tertiary care hospital. Int J Pharm Pharm Sci 2016;8(8):375-7.

8. Vijaya PV, Suja V, Devi CS. Hepatoprotective effect of liv.52 on antitubercular drug-induced hepatotoxicity in rats. Fitoterapia 1998;LXIX:520-3.

9. Funde SK, Jaju JB, Dharmadhikari SC, Pawar GR. Effect of Lagenaria siceraria fruit extract (Bottle gourd) on hepatotoxicity induced by antitubercular drugs in albino rats. Int $\mathrm{J}$ Basic Clin Pharmacol 2013;2(6):728-34.

10. Samuel AJ, Mohan S, Chellappan DK, Kalusalingam A, Ariamuthu S. Hibiscus vitifolius (Linn.) root extracts shows potent protective action against anti-tubercular drug induced hepatotoxicity. J Ethnopharmacol 2012;141(1):396-402.

11. Kale BP, Kothekar MA, Tayade HP, Jaju JB, Mateenuddin M. Effect of aqueous extract of Azadirachta indica Leaves on hepatotoxicity induced by antitubercular drugs in rats. Indian J Pharmacol 2003;35:177-80.

12. Gamble M. The hematoxylins and eosin. In: Bancroft JD, Gamble M, editors. Theory and Practice of Histological Techniques. $6^{\text {th }}$ ed. London: Churchill Livingstone Elsevier; 2008. p. 121-4.

13. Jaeschke H, Gores GJ, Cederbaum AI, Hinson JA, Pessayre D, Lemasters JJ. Mechanisms of hepatotoxicity. Toxicol Sci 2002;65(2):166-76.

14. Mehta S. Malnutrition and drugs: Clinical implications. Dev Pharmacol Ther 1990;15(3-4):159-65.

15. Pande JN, Singh SP, Khilnani GC, Khilnani S, Tandon RK. Risk factors for hepatotoxicity from antituberculosis drugs: A case-control study. Thorax 1996;51(2):132-6.

16. Ostapowicz G, Fontana RJ, Schiødt FV, Larson A, Davern TJ, Han $\mathrm{SH}$, et al. Results of a prospective study of acute liver failure at 17 tertiary care centers in the United States. Ann Intern Med 2002;137(12):947-54.

17. Saukkonen JJ, Cohn DL, Jasmer RM, Schenker S, Jereb JA, Nolan CM, et al. An official ATS statement: Hepatotoxicity of antituberculosis therapy. Am J Respir Crit Care Med 2006;174(8):935-52.

18. Sodhi CP, Rana SV, Mehta SK, Vaiphei K, Attri S, Thakur S, et al. Study of oxidative stress in isoniazid-induced hepatic injury in young rats with and without protein-energy malnutrition. J Biochem Toxicol 1996;11(3):139-46

19. Metushi IG, Cai P, Zhu X, Nakagawa T, Uetrecht JP. A fresh look at the mechanism of isoniazid-induced hepatotoxicity. Clin Pharmacol Ther 2011;89(6):911-4.

20. Hussain Z, Kar P, Husain SA Antituberculosis drug-induced hepatitis: Risk factors, prevention and management. Indian J Exp Biol 2003;41(11):1226-32.

21. Tostmann A, Boeree MJ, Aarnoutse RE, de Lange WC, van der Ven AJ, Dekhuijzen R. Antituberculosis drug-induced hepatotoxicity: Concise up-to-date review. J Gastroenterol Hepatol 2008;23(2):192-202.

22. Sarma GR, Immanuel C, Kailasam S, Narayana AS, Venkatesan P. Rifampin-induced release of hydrazine from isoniazid. A possible cause of hepatitis during treatment of tuberculosis with regimens containing isoniazid and rifampin. Am Rev Respir Dis 1986;133(6):1072-5

23. Whitehouse LW, Lodge BA, By AW, Thomas BH. Metabolic disposition of pyrazinamide in the rat: Identification of a novel in vivo metabolite common to both rat and human. Biopharm Drug Dispos 1987;8(4):307-18

24. Lacroix C, Hoang TP, Nouveau J, Guyonnaud C, Laine G, Duwoos H, et al. Pharmacokinetics of pyrazinamide and its metabolites in healthy subjects. Eur J Clin Pharmacol 1989;36(4):395-400.

25. Metushi IG, Nakagawa T, Uetrecht J. Direct oxidation and covalent binding of isoniazid to rodent liver and human hepatic microsomes: Humans are more like mice than rats. Chem Res Toxicol 2012;25(11):2567-76.

26. O'Brien PJ, Slaughter MR, Polley SR, Kramer K. Advantages of glutamate dehydrogenase as a blood biomarker of acute hepatic injury in rats. Lab Anim 2002;36(3):313-21.

27. Ng W, Lobach AR, Zhu X, Chen X, Liu F, Metushi IG, et al. Animal models of idiosyncratic drug reactions. Adv Pharmacol 2012;63:81-135.

28. Mehmedagic A, Vérité P, Ménager S, Tharasse C, Chabenat C, André D, et al. Determination of pyrazinamide and its main metabolites in rat urine by high-performance liquid chromatography. J Chromatogr B Biomed Sci Appl 1997;695(2):365-72.

29. Stout JE, Engemann JJ, Cheng AC, Fortenberry ER, Hamilton CD. Safety of 2 months of rifampin and pyrazinamide for treatment of latent tuberculosis. Am J Respir Crit Care Med 2003;167(6):824-7.

30. Yee D, Valiquette C, Pelletier M, Parisien I, Rocher I, Menzies D. Incidence of serious side effects from first-line antituberculosis drugs among patients treated for active tuberculosis. Am J Respir Crit Care Med 2003;167(11):1472-7. 